\title{
Avaliação da qualidade da água e cargas difusas em microbacias hidrográficas - estudo de caso na bacia do rio Ribeirão da Serra (Poços de Caldas-MG)
}

\section{Water quality assessment and diffuse loads in watersheds - a case study in the Ribeirão da Serra river (Poços de Caldas-MG)}

Leandro Henrique da Silva Engenheiro Ambiental/UNIFAL-MG, Brasil lhenriquesilva20@gmail.com

Rafael Ricardo de Melo Trevisan Engenheiro Ambiental/UNIFAL-MG, Brasil Rafael Trevisan@hotmail.com

Antonio Donizetti Gonçalves de Souza Doutor em Ecologia e Recursos Naturais e Docente ICT/UNIFAL-MG, Brasil adonizetti@,unifal-mg.edu.br

Diego de Souza Sardinha Doutor em Geologia Regional e Docente ICT/UNIFAL-MG, Brasil diego.sardinha@unifal-mg.edu.br

\section{Resumo}

A poluição de corpos hídricos superficiais por cargas difusas configura-se em um dos maiores problemas ambientais atuais. O presente trabalho teve como objetivo avaliar a qualidade da água e as cargas difusas de poluição hídrica na bacia hidrográfica do rio Ribeirão da Serra (Poços de Caldas-MG). Para a avaliação da qualidade da água foram estabelecidos dois pontos de amostragem, o ponto $1(\mathrm{P} 1)$ localizado na região das nascentes e o ponto $2(\mathrm{P} 2)$ em área urbana. Nestes pontos foram medidas, em dois períodos sazonais (chuvoso e estiagem), as seguintes variáveis: temperatura, condutividade, oxigênio dissolvido, sólidos totais dissolvidos, sólidos totais suspensos, fósforo total e vazão. Para a estimativa do aporte de cargas difusas na bacia, foi produzido um mapa de uso e ocupação do solo e utilizado o Modelo Matemático de Correlação Uso do Solo e Qualidade da Água (MQUAL). Os resultados demonstraram a influência da área urbana na qualidade da água para as variáveis condutividade, sólidos totais dissolvidos e fósforo total com valores elevados no ponto $\mathrm{P} 2$. Com relação às cargas difusas, o modelo permitiu verificar que os maiores aportes diários de nitrogênio total, DBO, sólidos totais suspensos e coliformes totais, foram provenientes da área urbana da bacia. Isto indica os impactos que esta área provoca no meio aquático. $\mathrm{O}$ presente estudo pode subsidiar o desenvolvimento de metodologias regionais de avaliação de cargas poluidoras difusas em bacias existentes no município. Além disto, pode incentivar os gestores locais à tomada de decisões no que concerne ao planejamento adequado do uso e ocupação do solo em bacias hidrográficas urbanas.

Palavras-chave: Cargas Difusas; Poluição Hídrica; Qualidade da Água; Bacia Hidrográfica. 


\begin{abstract}
The pollution of surface water bodies by diffuse charges is one of the biggest current environmental problems. The presentation evaluated water quality and diffuse water pollution loads in the Ribeirão da Serra River (Poços de Caldas-MG). To assess water quality, two sampling points were established, point 1 (P1) located in the region of springs and point 2 (P2) in an urban area. The following variables were measured in two seasonal periods (rainy and dry): temperature, conductivity, dissolved oxygen, total dissolved solids, total suspended solids, total phosphorus and flow. A land use and occupation map was produced to estimate the contribution of diffuse loads in the basin, and the Mathematical Model of the Correlation of Land Use and Water Quality (MQUAL) was used. The results showed the influence of the urban area on water quality for the variables conductivity, total dissolved solids and total phosphorus with high values at point P2. Regarding the diffuse loads, the model allowed us to verify that the largest daily contributions of total nitrogen, BOD, total suspended solids and total coliforms came from the urban area of the basin. This indicates the impacts that this area has on the aquatic environment. Therefore, this study can support the development of regional methodologies for assessing diffuse pollutant loads in existing basins in the municipality. In addition, it can encourage local managers to make decisions regarding the proper planning of land use and occupation in urban watersheds.
\end{abstract}

Keywords: Diffuse Loads; Water Pollution; Water Quality; Watershed.

\title{
1. INTRODUÇÃO
}

A qualidade da água resulta da interação entre os fenômenos naturais e antrópicos, sendo que suas características e disponibilidade, quando em estado natural, dependem principalmente do clima e das características físicas e biológicas da bacia hidrográfica (MORUZZI et al., 2012).

Segundo Souza e Souza (2015), a poluição de corpos hídricos superficiais é um dos maiores problemas ambientais atualmente existentes, causando efeitos negativos para a saúde humana e ambiental e, muitas vezes, influenciando e prejudicando a qualidade da água para seus diversos usos. Desta forma, as fontes de poluição da água podem ser classificadas em duas tipologias, pontuais e difusas.

A poluição difusa é composta por cargas que atingem o curso d'água de forma intermitente, ou seja, de forma não uniforme. O termo "poluição difusa" é caracterizado como sendo a carga ou poluente que ingressa ao curso d'água, de maneira numerosa e espalhada. Um de seus principais agravantes é o escoamento da água de precipitações em áreas urbanas, carreando inúmeros poluentes para os corpos hídricos (CAMPBELL, 2004).

Segundo Novotny (2003) as condições que caracterizam as fontes de poluição difusa podem ser resumidas da seguinte forma: a) o lançamento da carga poluidora é intermitente e está relacionado basicamente à precipitação e aos usos do solo na bacia; b) os poluentes são transportados a partir de extensas áreas e c) as cargas poluidoras não podem ser monitoradas a partir de seu ponto original, mesmo porque não é possível identifica-lo. 
As avaliações de cargas difusas em bacias hidrográficas são consideradas primordiais para a fundamentação de proposições e hipóteses que visam estabelecer a ocorrência, assim como as possíveis fontes poluidoras que geraram e são potenciais contribuintes do acréscimo da carga em cursos d'água.

Para Bonumá et al., (2008) o escoamento superficial no início de uma chuva (first flush) é que carrega grande concentração de poluentes que ficaram acumulados nos dias sem chuva. Portanto, em períodos chuvosos a determinação de cargas difusas se torna ainda mais difícil pelo fato que muitas partículas grosseiras, sedimentos que são oriundos de ruas, lotes, indústrias, galerias, dentre outros, são carreadas para os cursos d'água.

Os estudos de cargas difusas são aplicáveis em áreas industriais, residenciais e comerciais, ou seja, localidades com potencial poluidor que são cortadas por rio, córregos e mananciais. Sua importância se dá pela necessidade de conhecer melhor seus tipos e fontes a fim de mitigar os efeitos negativos gerados nos recursos hídricos.

Segundo Lee e Bang (2000) conhecer os mecanismos pelos quais os poluentes difusos se mobilizam no meio ambiente é essencial para o desenvolvimento de estratégias de prevenção e controle dos mesmos.

O processo de modelagem e simulação da poluição difusa está associado a uma série de desafios, uma vez que as fontes e os caminhos são de difícil rastreio. Alguns dos mais notórios e compatíveis com a realidade brasileira são: aquisição e disponibilidade de dados, precisão de bases de dados e suas implicações em parâmetros de modelagem, capacidade de um modelo em reproduzir adequadamente usos do solo tipicamente urbanos e/ou rurais, desempenho do modelo em simular adequadamente regimes áridos e performance do modelo em simular com baixa quantidade de dados (FERREIRA et al., 2018).

Os modelos matemáticos relacionados à poluição difusa são complexos e, muitas vezes, são destinados a aplicações em bacias relativamente pequenas. Segundo Ferreira et al., (2018) o grande diferencial e desafio dos modelos de poluição difusa está na capacidade de representar as características de uso e ocupação do solo associadas à representação dos processos hidrológicos na bacia.

O Modelo Matemático de Correlação Uso do Solo e Qualidade da Água (MQUAL) foi criado pela Secretaria Estadual de Meio Ambiente de São Paulo com o objetivo de quantificar a geração de cargas pontuais e difusas de poluentes que atingem os corpos d'água em uma bacia hidrográfica. Este modelo foi apresentado durante a formulação do Programa de Saneamento Ambiental da Bacia do Guarapiranga - Programa Guarapiranga (SMA, 2003).

O MQUAL correlaciona o uso do solo com a qualidade da água, sendo considerados três pilares: (1) Geração de carga, (2) Simulação do reservatório, e (3) Simulação dos principais 
tributáveis (SOUZA e MINOTI, 2010). Os três pilares são representações dos fenômenos de geração e autodepuração das cargas poluidoras considerando três ambientes: cobertura do terreno, os corpos d'água e seus tributários e o reservatório.

Neste contexto a bacia hidrográfica do rio Ribeirão da Serra, localizado no município de Poços de Caldas (MG), possui nascentes em área rural e exutório na área central urbana. O rio recebe fontes difusas de poluição tanto de origem agrícola como provenientes da drenagem urbana ao longo de seu curso. Além disto, este corpo hídrico se constitui em um dos mananciais do município.

O presente trabalho teve como objetivos avaliar a qualidade da água e as cargas difusas de poluição hídrica na bacia hidrográfica do rio Ribeirão da Serra (Poços de Caldas- MG) aplicando o modelo MQUAL (SMA, 2003).

\section{METODOLOGIA}

\section{1. Área de Estudo}

O município de Poços de Caldas está localizado ao sul do estado de Minas Gerais, inserido na borda ocidental da Serra da Mantiqueira (21 ${ }^{\circ} 50$ '20”S e 46 ${ }^{\circ} 33^{\prime} 53$ ”W), possuindo uma população estimada de 169.838 habitantes em uma unidade territorial de 547,061 km² (IBGE, 2021). As principais atividades econômicas são mineração, agricultura, pecuária, silvicultura, turismo, artesanato e agroindústria.

O clima de Poços de Caldas, segundo a classificação de Köppen, é do tipo Cwb, mesotérmico com inverno seco e verão brando. Este é marcado pela ocorrência de duas estações distintas: o verão chuvoso (outubro a março), caracterizado pelas temperaturas e precipitações elevadas (temperatura média de $20,3{ }^{\circ} \mathrm{C}$ e total no período de $1430 \mathrm{~mm}$ de chuvas) e o inverno, seco (abril a setembro) marcado por temperaturas e índices pluviométricos baixos (temperatura média de $15^{\circ} \mathrm{C}$ e $315 \mathrm{~mm}$ de chuvas no período). A precipitação média anual é de $1.745 \mathrm{~mm}$ (FERNANDES, 2003).

A bacia hidrográfica do rio Ribeirão da Serra é a de maior dimensão dentro do limite urbano de Poços de Caldas (MG), o que implica em grande influência sobre a qualidade da água deste curso hídrico. A bacia faz uma transição entre uma área rural e a região central urbana do município estendendo-se por uma área de 29,33 km² (Figuras 1 e 2). 

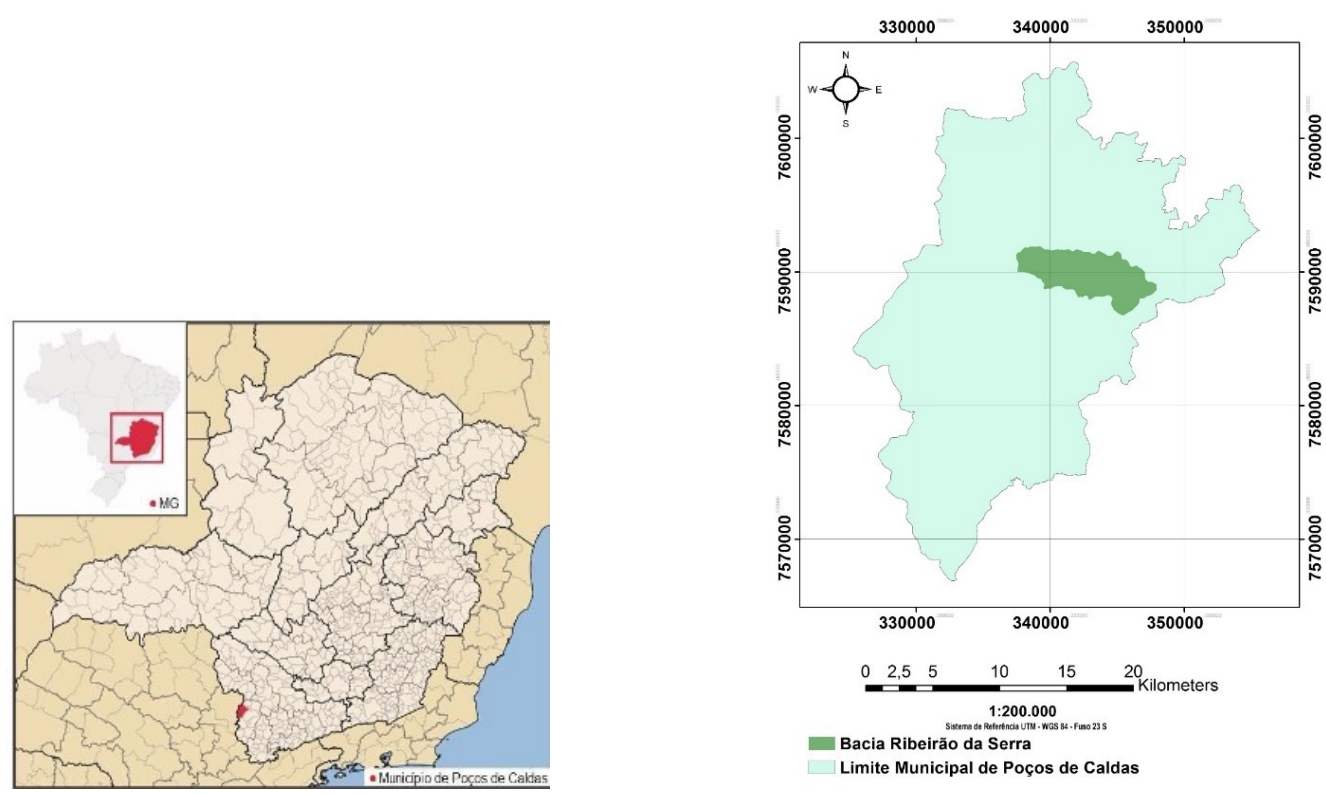

Figura 1 - Localização do município de Poços de Caldas e da bacia do Ribeirão da Serra.

Fonte: Dos autores.

\subsection{Avaliação da Qualidade da Água}

As coletas das amostras de água foram realizadas em dois pontos na bacia do rio Ribeirão da Serra (Figura 2).

O ponto $1(\mathrm{P} 1)$, situado a montante da área urbana, área de mata nativa, solos expostos, reflorestamento e pastagens. Portanto, caracterizada, preferencialmente, como zona rural. O ponto 2 (P2) localiza-se em região urbana, no exutório da bacia, área sujeita a todos os poluentes inerentes ao centro urbano.

As coletas foram realizadas em dois períodos sazonais, chuvoso $(29 / 03 / 2019)$ e estiagem (24/07/2019).

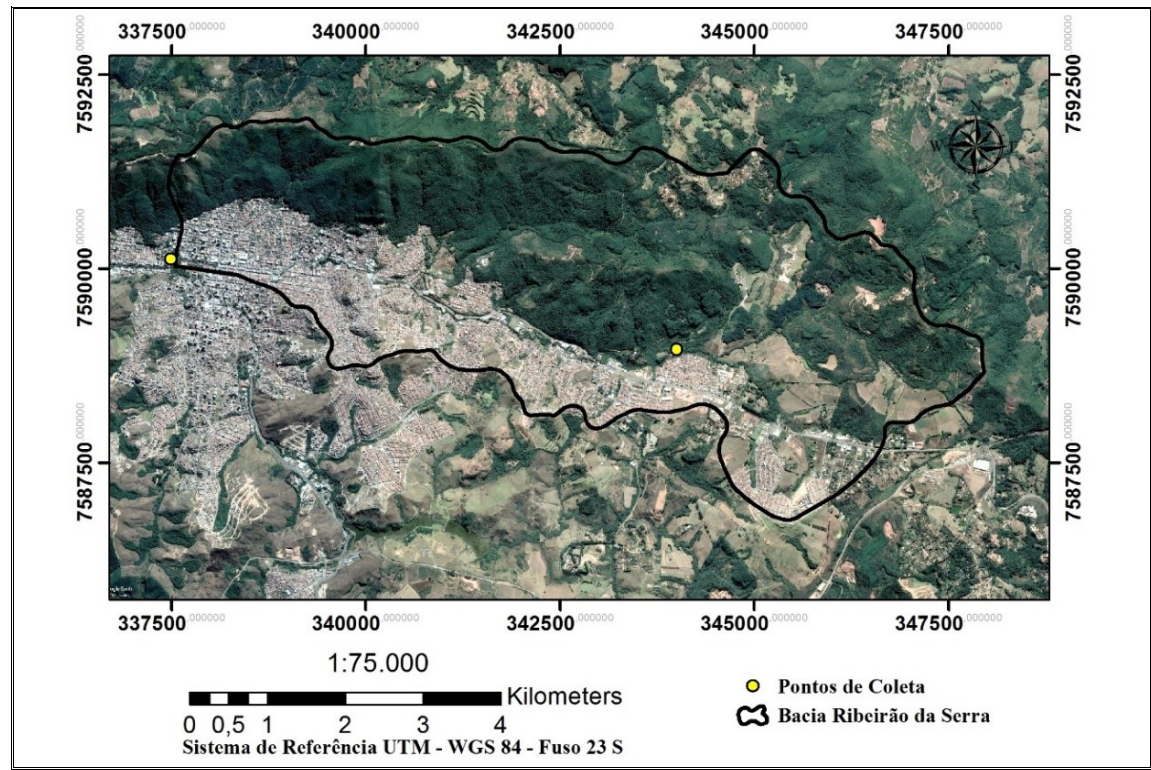

Figura 2 - Bacia do Ribeirão da Serra com os locais de coleta.

Fonte: Dos autores. 
Em campo foram medidas as seguintes variáveis: temperatura $\left({ }^{\circ} \mathrm{C}\right)$, condutividade elétrica $(\mu \mathrm{S} / \mathrm{cm})$, oxigênio dissolvido $(\mathrm{mg} / \mathrm{L})$ e sólidos totais dissolvidos $(\mathrm{mg} / \mathrm{L})$. As medidas foram realizadas com sonda multiparâmetro ProDSS da marca YSI. As características da sonda para as variáveis medidas são apresentadas na tabela 1.

Tabela 1 - Especificações das medidas da sonda multiparâmetro ProDSS (YSI).

\begin{tabular}{cccc}
\hline Variável & Faixa de Medida & Resolução & Acurácia \\
\hline Temperatura & -5 a $55^{\circ} \mathrm{C}$ & $0,1^{\circ} \mathrm{C}$ & $\pm 0,3^{\circ} \mathrm{C}$ \\
Oxigênio Dissolvido & 0 a $20 \mathrm{mg} / \mathrm{L}$ & $0,1 \mathrm{mg} / \mathrm{LO}$ & $\pm 2 \%$ da leitura ou $\pm 0,2 \mathrm{mg} / \mathrm{L}$ \\
Condutividade & 0 a $500 \mu \mathrm{S} / \mathrm{cm}$ & $0,1 \mathrm{a} 0 \mu \mathrm{S} / \mathrm{cm}$ & $\pm 1 \%$ da leitura ou $\pm 1 \mu \mathrm{S} / \mathrm{cm}$ \\
Sólidos Totais & 0 a $100 \mathrm{~g} / \mathrm{L}$ & $0,0001 \mathrm{a} 0,1 \mathrm{~g} / 1$ & $\begin{array}{c}\text { Em função de temperatura e } \\
\text { condutividade }\end{array}$ \\
Dissolvidos & & & \\
\hline
\end{tabular}

Fonte: YSI (2014).

Com os valores de temperatura $\left({ }^{\circ} \mathrm{C}\right)$ da água e altitude $(\mathrm{m})$ obtida com GPS, foi calculado o percentual de saturação de oxigênio (\% Saturação OD) segundo equações de Von Sperling (2014).

Além destas variáveis, foram coletadas amostras para análise em laboratório de sólidos totais suspensos $(\mathrm{mg} / \mathrm{L})$ e fósforo total $(\mathrm{mg} / \mathrm{L})$.

As análises de sólidos totais suspensos foram feitas segundo técnica de filtração e gravimetria descrita em Teixeira et al., (1965) e Tundisi (1969). O fósforo total foi determinado segundo Strickland e Parsons (1960) e Valderrama (1981), que consiste na digestão oxidativa da amostra com persufato de potássio em autoclave a $120{ }^{\circ} \mathrm{C}$, posterior reação com molibdato de amônia e ácido ascórbico e leitura em espectrofotômetro a $882 \mathrm{~nm}$.

\subsection{Dados Pluviométricos (mm)}

Os dados pluviométricos (mm) foram obtidos no Departamento Municipal de Água e Esgoto de Poços de Caldas (DMAE) em estação localizada próximo a área urbana. Foram obtidos os dados das precipitações totais mensais para o ano de 2019.

\subsection{Medidas de Vazão (m3/s)}

A vazão $\left(\mathrm{m}^{3} / \mathrm{s}\right)$ foi determinada nos dois pontos de coleta (P1 e P2) nos mesmos dias das coletas de amostra de água. Para as medidas de vazão foi utilizado o método flutuador. Este método consiste em determinar área da seção $\left(\mathrm{m}^{2}\right)$ e a velocidade média do fluxo que passa por tal área $(\mathrm{m} / \mathrm{s})$. Para a determinação da velocidade média do fluxo $(\mathrm{m} / \mathrm{s})$, foram estabelecidos dois pontos foi medido o tempo de deslocamento do flutuador. A vazão foi determinada pela equação 01 .

$$
Q=v \cdot A
$$


Onde:

$\mathrm{Q}=\operatorname{Vazão}\left(\mathrm{m}^{3} / \mathrm{s}\right)$.

$v=$ Velocidade $(\mathrm{m} / \mathrm{s})$.

$\mathrm{A}=$ Área da seção do rio $\left(\mathrm{m}^{2}\right)$.

\subsection{Cargas Difusas - Aplicação do modelo MQUAL}

Para utilizar o modelo MQUAL e determinar as cargas difusas na bacia estudada foi utilizada a carta de uso e ocupação do solo produzida a partir de imagem do Google Earth PRO para o ano de 2018.

A tabela 2 apresenta os diferentes coeficientes de exportação (CE) determinados pela Secretaria Estadual de Meio Ambiente e utilizados pelo modelo MQUAL para cada uma das categorias de ocupação do solo adotadas pelo modelo. Desta forma, as áreas das classes temáticas do mapa de uso e ocupação do solo foram divididas de acordo com o modelo MQUAL.

Tabela 2 - Coeficientes de exportação para cargas difusas $\left(\mathrm{kg} /\left(\mathrm{km}^{2}\right.\right.$.dia $)$ do modelo MQUAL.

\begin{tabular}{lccccc}
\hline \multicolumn{1}{c}{ FONTES } & $\begin{array}{c}\text { Fósforo } \\
\text { Total }\end{array}$ & $\begin{array}{c}\text { Nitrogênio } \\
\text { Total }\end{array}$ & DBO & STS & $\begin{array}{c}\text { Coliformes } \\
\text { Totais }\end{array}$ \\
\hline Atividade Agrícola & 0,346 & 2,950 & 7,320 & 230,000 & $100,0 \times 10^{9}$ \\
Reflorestamento & 0,039 & 0,600 & 1,200 & 20,000 & $0,1 \times 10^{9}$ \\
Pastagem & 0,050 & 0,900 & 2,250 & 40,000 & $1,0 \times 10^{9}$ \\
Mata/Capoeirão/Mata galeria & 0,039 & 0,600 & 1,200 & 20,000 & $0,1 \times 10^{9}$ \\
Capoeira/Campo & 0,028 & 0,500 & 1,060 & 30,000 & $0,1 \times 10^{9}$ \\
Solo Exposto & 0,034 & 1,270 & 5,540 & 50,000 & $1,0 \times 10^{9}$ \\
Áreas Urbanas & 0,034 & 1,270 & 5,540 & 50,000 & $1,0 \times 10^{9}$ \\
\hline
\end{tabular}

Fonte: SMA (2003).

O cálculo das cargas difusas (CD) geradas pelo modelo foi realizado pela Equação 02.

$$
C D=A \cdot C E
$$

Onde:

CD: Carga difusa (kg/dia).

A: Área total de cada classe proposta de uso e ocupação do solo $\left(\mathrm{km}^{2}\right)$.

CE: Coeficiente de exportação $\left(\mathrm{kg} /\left(\mathrm{km}^{2}\right.\right.$.dia $)$.

\section{RESULTADOS E DISCUSSÃO}

A figura 3 apresenta os índices pluviométricos registrados no ano de estudo. Pode-se observar que os dois meses de medidas de qualidade da água e vazão correspondem ao período chuvoso (março/2019) e de estiagem (julho/2019). 


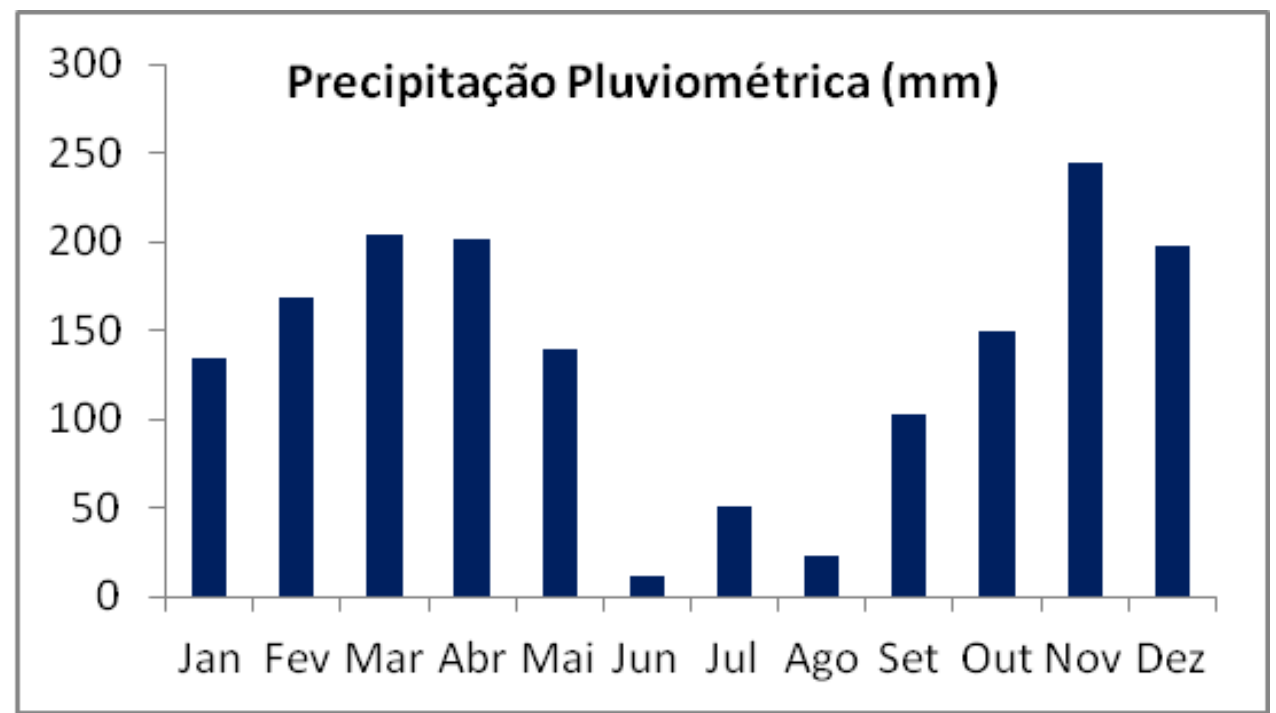

Figura 3 - Índices pluviométricos registrados no ano de 2019 para área de estudo. Fonte: DMAE (2019).

A Tabela 3 apresenta os valores obtidos das vazões nos dois pontos de amostragem para os períodos estudados.

Tabela 3 - Vazões do curso d'água obtidas através do método do flutuador.

\begin{tabular}{ccc}
\hline Ponto & Período & $\mathbf{Q}\left(\mathbf{m}^{\mathbf{3}} / \mathbf{s}\right)$ \\
\hline \multirow{2}{*}{ P1 } & Estiagem & 0,229 \\
& Chuvoso & 0,462 \\
P2 & Estiagem & 0,659 \\
& Chuvoso & 2,299 \\
\hline
\end{tabular}

Fonte: Dos autores.

Os resultados obtidos das vazões foram os esperados para os períodos e pontos de coleta. A maior vazão foi registrada no Ponto 2 (exutório da bacia) no período chuvoso $\left(2,299 \mathrm{~m}^{3} / \mathrm{s}\right.$ ) e o menor valor foi encontrado no Ponto 1 na época de estiagem $\left(0,229 \mathrm{~m}^{3} / \mathrm{s}\right)$.

Na tabela 4 e figuras 4 a 6 são apresentados os resultados das variáveis de qualidade da água obtidos nos dois pontos de amostragem.

Tabela 4: Resultados da qualidade da água na bacia do rio Ribeirão da Serra.

\begin{tabular}{ccccccccc}
\hline \multirow{2}{*}{ Ponto } & Períodos & $\begin{array}{c}\text { Temp. } \\
\left({ }^{\circ} \mathbf{C}\right)\end{array}$ & $\begin{array}{c}\text { OD } \\
(\mathbf{m g} / \mathbf{L})\end{array}$ & $\begin{array}{c}\text { Sat. OD } \\
(\mathbf{\%})\end{array}$ & $\begin{array}{c}\text { Cond. } \\
(\boldsymbol{\mu S} / \mathbf{c m})\end{array}$ & $\begin{array}{c}\text { STD } \\
(\mathbf{m g} / \mathbf{L})\end{array}$ & $\begin{array}{c}\text { STS } \\
(\mathbf{m g} / \mathbf{L})\end{array}$ & $\begin{array}{c}\text { Fósforo Total } \\
(\mathbf{m g} / \mathbf{L})\end{array}$ \\
\hline \multirow{2}{*}{ P1 } & Estiagem & 11,80 & 7,70 & 82,73 & 42,30 & 36,80 & 1,17 & 0,0409 \\
& Chuvoso & 18,20 & 7,80 & 96,62 & 36,50 & 27,20 & 7,35 & 0,0100 \\
\multirow{2}{*}{ P2 } & Estiagem & 14,70 & 7,20 & 78,90 & 81,20 & 65,80 & 5,03 & 0,0842 \\
& Chuvoso & 19,00 & 7,50 & 90,15 & 71,00 & 52,10 & 6,82 & 0,0768 \\
\hline
\end{tabular}




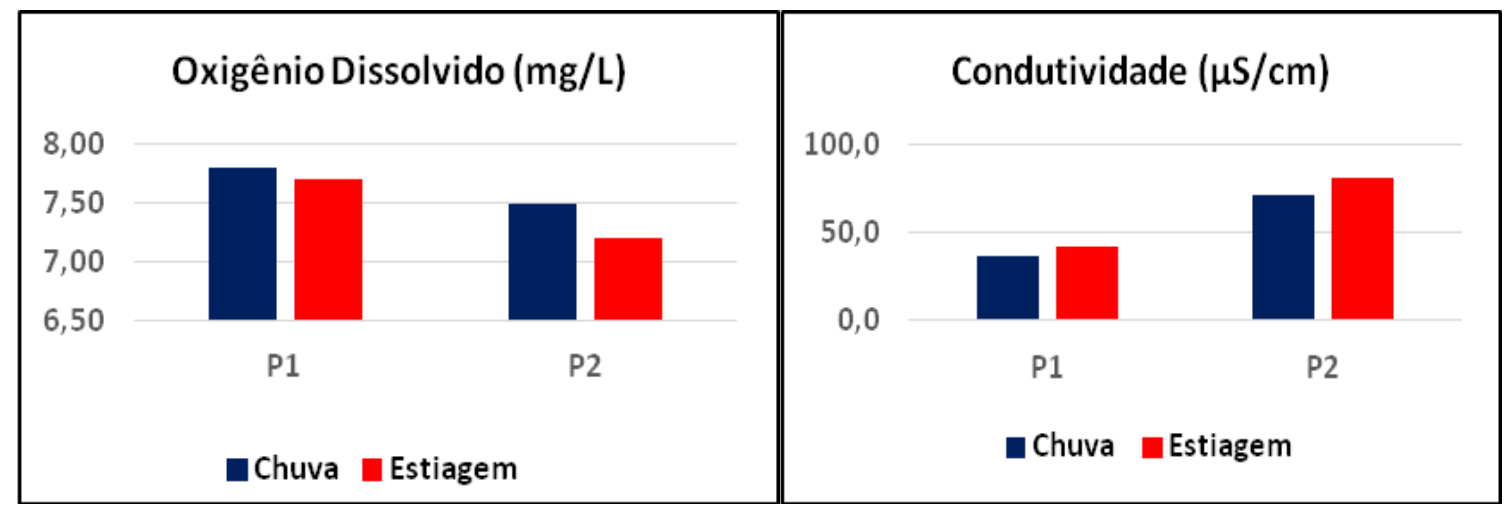

Figura 4 - Variação espacial de OD e condutividade nos pontos de amostragem.

Fonte: Dos autores.

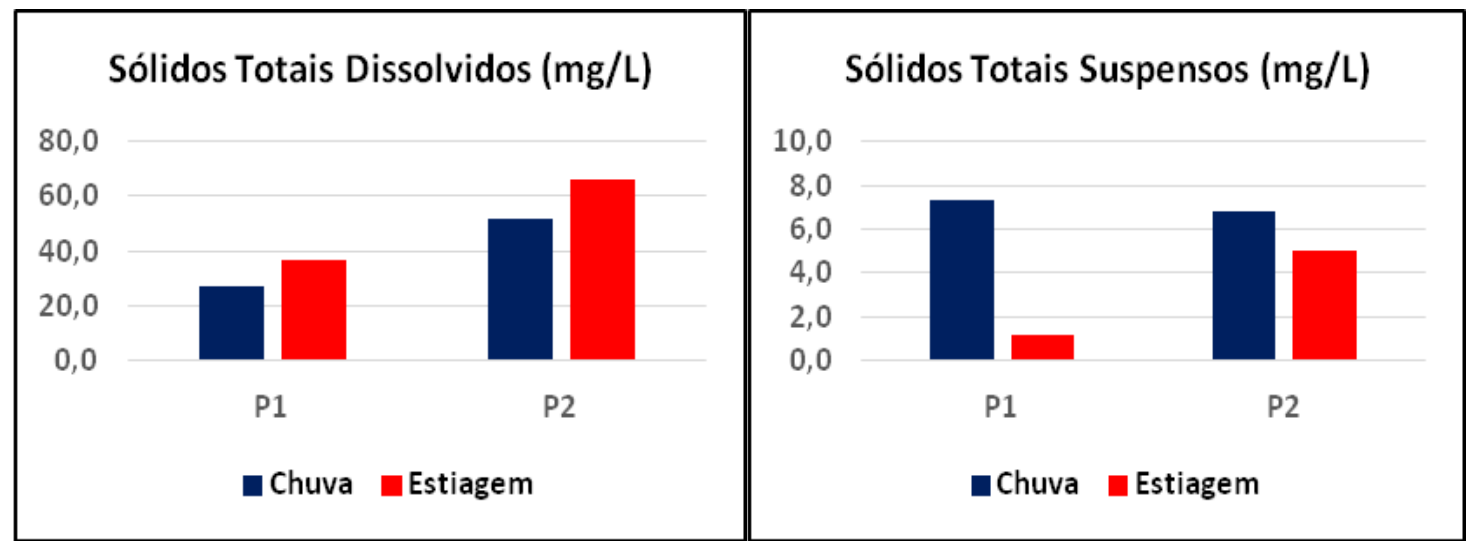

Figura 5 - Variação espacial de STD e STS nos pontos de amostragem.

Fonte: Dos autores

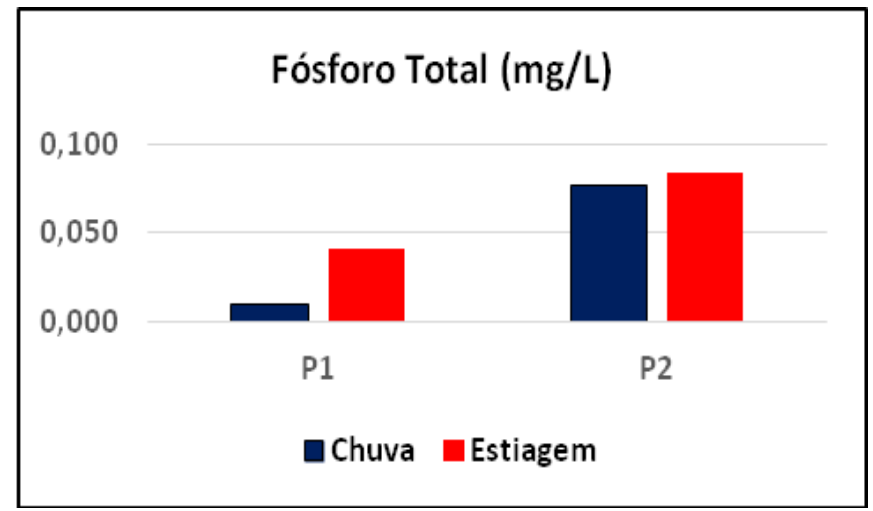

Figura 6 - Variação espacial de fósforo total nos pontos de amostragem.

Fonte: Dos autores

O maior valor de oxigênio dissolvido (OD) foi observado no Ponto 1, no período chuvoso e o menor no Ponto 2, na estação de estiagem. Considerando o valor da Resolução CONAMA 357/2005 (BRASIL, 2005) para rios de Classe 2, OD $\geq 5,0 \mathrm{mg} / \mathrm{L}$, todos os valores obtidos para esta variável estão em conformidade com este normativo legal.

Com relação a condutividade, o valor mais elevado foi obtido Ponto $2(81,20 \mu \mathrm{S} / \mathrm{cm})$ durante a estiagem e o menor no Ponto 1 durante a época de chuvas $(36,50 \mu \mathrm{S} / \mathrm{cm})$. A concentração de sólidos totais dissolvidos (STD) seguiu o padrão encontrado para a variação da condutividade, 
uma vez que as duas variáveis refletem a presença de íons na água. O Ponto 2 apresentou o maior valor no período de estiagem $(65,80 \mathrm{mg} / \mathrm{L})$.

Os valores elevados de condutividade e STD no Ponto 2 podem estar relacionados ao efeito da concentração das cargas poluidoras em períodos de estiagem proveniente da ocupação urbana. Vários autores reportam aumento de índices iônicos na água em rios que atravessam áreas urbanas. Sardinha et al., (2008) estudando o rio Ribeirão do Meio em Leme (SP), observaram valores baixos de condutividade nas nascentes e valores elevados após o curso d'água atingir a área urbana da cidade em período chuvoso. Souza e Gastaldini (2014) também verificaram o aumento de condutividade devido influência da urbanização na bacia hidrográfica do Rio Vacacaí-Mirim (RS).

Os sólidos totais suspensos (STS) estão relacionados ao arraste de materiais pelas águas provenientes das precipitações e ocupação do solo. Isto foi obtido nos resultados encontrados para o Ponto P2 no período chuvoso. Medeiros et al., (2018) e Palhares et al., (2012) também encontraram variações semelhantes de sólidos totais suspensos em períodos chuvosos em águas superficiais naturais.

Valores elevados da concentração de fósforo total em rios geralmente são provenientes de fontes antropogênicas, tais como: uso de fertilizantes na agricultura e lançamentos de efluentes domésticos e industriais (VON SPERLING, 2014). Segundo a Resolução CONAMA 357/2005, para rios de Classe 2, o limite de fósforo total para ambientes lóticos é de $0,100 \mathrm{mg} / \mathrm{L}$. Nos pontos amostrados na bacia do Ribeirão da Serra, com exceção do Ponto 1, todos os pontos ultrapassaram este valor. O Ponto 2 apresentou os maiores valores nos dois períodos sazonais $(0,0842 \mathrm{mg} / \mathrm{L}$ e $0,0768 \mathrm{mg} / \mathrm{L}$ ), ou seja, cerca de 8 vezes o valor máximo permitido para a Classe 2 da CONAMA $357 / 2005$. Estes valores provavelmente indicam a presença de fontes poluidoras existentes no curso d'água, principalmente na área urbana.

Para a aplicação do modelo MQUAL foi produzido o mapa de uso e ocupação do solo (Figura 7). A tabela 5 apresenta a quantificação das áreas segundo as classes do modelo. 


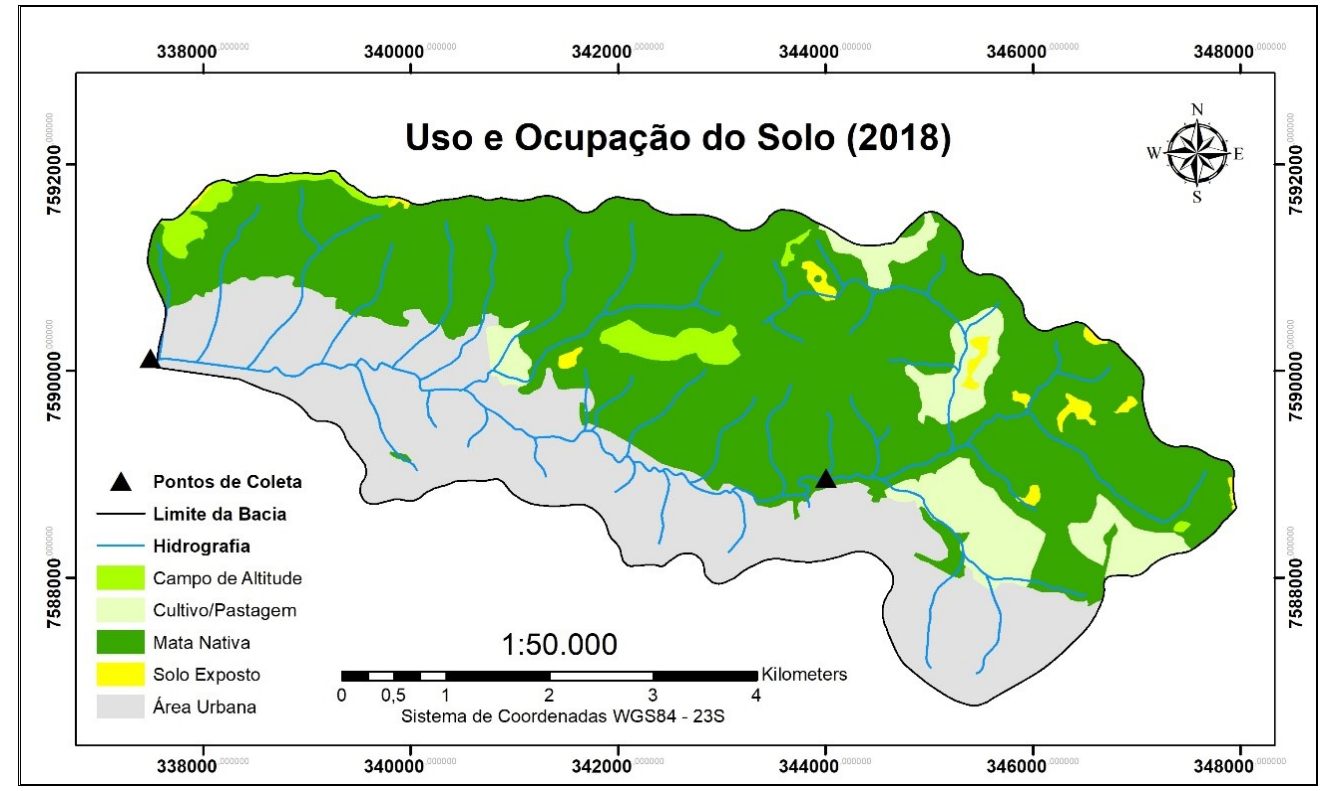

Figura 7 - Mapa de uso e ocupação do solo na bacia do Ribeirão da Serra no ano de 2018.

Fonte: Dos autores.

Tabela 5: Uso e Ocupação do solo na bacia do Ribeirão da Serra.

\begin{tabular}{ccc}
\hline Tipo de Ocupação & Área $\mathbf{( k m}^{\mathbf{2}} \mathbf{)}$ & Área (\%) \\
\hline Campo de Altitude & 0,69 & 2,35 \\
Cultivo/Pastagem & 2,25 & 7,67 \\
Mata Nativa & 16,74 & 57,07 \\
Solo Exposto & 0,32 & 1,08 \\
Área Urbana & 9,33 & 31,82 \\
Total & 29,33 & 100,00 \\
\hline
\end{tabular}

Fonte: Dos Autores.

Após o emprego dos coeficientes de exportação (CE) do modelo MQUAL e aplicação da Equação 02, foram obtidas as estimativas do aporte de cargas na bacia do Ribeirão da Serra (Tabela $6)$.

Tabela 6:- Aporte das cargas difusas calculadas pelo modelo MQUAL em função das áreas de ocupação na bacia do Ribeirão da Serra ( $\mathrm{kg} / \mathrm{dia})$.

\begin{tabular}{cccccc}
\hline FONTES & $\begin{array}{c}\text { Fósforo } \\
\text { Total }\end{array}$ & $\begin{array}{c}\text { Nitrogênio } \\
\text { Total }\end{array}$ & DBO & STS & $\begin{array}{c}\text { Coliformes } \\
\text { Totais }\end{array}$ \\
\hline Cultivo/Pastagem & 0,11 & 2,03 & 5,07 & 90,12 & $2,25 \times 10^{9}$ \\
Mata Nativa & 0,65 & 10,04 & 20,09 & 334,80 & $1,67 \times 10^{9}$ \\
Campo de Altitude & 0,02 & 0,35 & 0,73 & 20,70 & $0,07 \times 10^{9}$ \\
Solo Exposto & 0,01 & 0,40 & 1,76 & 15,90 & $0,32 \times 10^{9}$ \\
Áreas Urbanas & 0,32 & 11,86 & 51,71 & 466,70 & $9,33 \times 10^{9}$ \\
Total & $\mathbf{1 , 1 1}$ & $\mathbf{2 4 , 6 8}$ & $\mathbf{7 9 , 3 6}$ & $\mathbf{9 2 8 , 2 2}$ & $\mathbf{1 3 , 6 4 \times 1 0 ^ { 9 }}$ \\
\hline
\end{tabular}

Fonte: Dos autores.

Com relação ao nitrogênio total, $\mathrm{DBO}$, sólidos totais suspensos e coliformes totais, os maiores aportes diários foram devido às áreas urbanas $(11,86 \mathrm{~kg} / \mathrm{dia}, 51,71 \mathrm{~kg} / \mathrm{dia}, 466,70 \mathrm{~kg} / \mathrm{dia} \mathrm{e}$ 
$9,33 \times 10^{9} \mathrm{~kg} /$ dia, respectivamente), que podem estar relacionadas aos impactos que esta área pode provocar no meio aquático, exportando elevados níveis de materiais e poluentes.

Os estudos de Santos (2018) e Moruzzi et al., (2012), utilizando o MQUAL, identificaram que as áreas agrícolas apresentam as maiores taxas de contribuição em bacias hidrográficas onde há o predomínio deste tipo de ocupação. Este não é o caso da bacia do rio Ribeirão da Serra, onde há apenas $7,67 \%$ de sua área ocupada por atividades agrícolas. Por outro lado, a ocupação urbana corresponde a $31,82 \%$ da área da bacia, o que pode estar provocando a maior influência das cargas aportadas por este tipo de ocupação.

As maiores cargas de fósforo total, segundo o MQUAL, são provenientes de mata nativa seguidas das áreas urbanas. Este resultado também foi registrado por MARRA et al., (2019) na bacia do Rio das Mortes no município de Vassouras (RJ). Da mesma forma que outras cargas, a área urbana tem proporcionado inputs deste nutriente no corpo hídrico maior que a área agrícola.

Os dados de qualidade da água medidos indicaram correspondência com as cargas de aporte geradas pelo modelo MQUAL. Isto pode subsidiar estudos futuros que potencializem o monitoramento sistemático da qualidade da água visando calibração e desenvolvimento de modelos regionais de avaliação da poluição hídrica.

\section{CONSIDERAÇÕES FINAIS}

Na bacia hidrográfica do rio Ribeirão da Serra, os impactos antrópicos na qualidade da água foram verificados pelos elevados valores de condutividade, sólidos totais dissolvidos e fósforo total encontrados, principalmente no ponto P2, localizado no exutório da bacia, na área urbana do município de Poços de Caldas (MG). Estes valores indicaram a necessidade de medidas de proteção e continuidade das avaliações ao longo do tempo para adoção de medidas como o planejamento adequado do uso do solo e verificação de fontes de lançamentos (pontuais e difusos) no corpo hídrico.

A aplicação do modelo MQUAL se mostrou simples e adequada para se obter as estimativas do aporte das cargas difusas na bacia estudada. As cargas provenientes das áreas urbanas calculadas pelo modelo apresentaram correspondência com os resultados da qualidade da água. Isto reforça a necessidade de estudos mais aprofundados e contínuos voltados a estabelecer ações planejadas de uso e ocupação do solo e monitoramento da qualidade da água na bacia do rio Ribeirão da Serra.

O presente estudo pode ser utilizado como passo inicial para o desenvolvimento de uma metodologia regional de avaliação de cargas poluidoras difusas em bacias hidrográficas existentes no município. Além disto, pode incentivar os gestores locais à tomada de decisões no que concerne 
ao planejamento adequado do uso e ocupação do solo em bacias hidrográficas no meio urbano e rural.

\section{REFERÊNCIAS}

BONUMÁ, N. B.; GASTALDINI, M. C. C.; PAIVA, J. B. D. Análise da Carga Difusa de Poluição Gerada por Atividades de Mineração. RBRH - Revista Brasileira de Recursos Hídricos, v. 13, n. 3 , p. 105-115, 2008.

BRASIL. Resolução CONAMA No 357, de 17 de Março de 2005. Brasília (DF): Ministério do Desenvolvimento Urbano e Meio Ambiente, 2005.

CAMPBELL, N. S.; D’ARCY, B.; FROST, A.; NOVOTNY, V. Diffuse Pollution: An Introduction to the Problems and Solutions. London: IWA Publishing, 2004. 328p.

DMAE - Departamento Municipal de Água e Esgoto de Poços de Caldas. Relatório Anual Pluviométrico de 2019. Poços de Caldas: DMAE, 2019.

FERNANDES, M. R. Poços de Caldas, Caracterização de Ecossistemas. Empresa de Assistência Técnica e Extensão Rural do Estado de Minas Gerais - EMATER-MG - Relatório Técnico. 2003. $56 \mathrm{p}$.

FERREIRA, D. B.; MUHLENHOFF, A. P.; FERNANDES, C. V. S. Modelos de poluição difusa: desafios, estratégias e impactos para a gestão de recursos hídricos. Revista de Gestão de Águas da América Latina, v. 15, n. 10, p. 1-16, 2018.

IBGE - Instituto Brasileiro de Geografia e Estatística. Estimativas da População 2021. Disponível em: https://ftp.ibge.gov.br/Estimativas_de_Populacao/Estimativas_2021. Acesso em: 02 set. 2021.

LEE, J. H.; BANG, K. W. Characterization of Urban Stormwater Runoff. Water Research, v. 34, n. 6 , p. $1773-1780,2000$.

MARRA, E. B.; JUNIOR, J. A. M. PEREIRA, O. S.; AGUIAR, M. O. A. F.; PEREIRA, C. S. S. Avaliação da contribuição de cargas difusas na microbacia do rio das Mortes utilizando modelos matemáticos de correlação uso do solo e qualidade de água. In: CONGRESSO BRASILEIRO DE ENGENHARIA QUÍMICA EM INICIAÇÃO CIENTÍFICA. 12., 2019, São Paulo. Anais... São Paulo: 2019. p. 294-300.

MEDEIROS, W. M. V.; SILVA, C. E.; LINS, R. P. M. Avaliação sazonal e espacial da qualidade das águas superficiais da bacia hidrográfica do rio Longá, Piauí, Brasil. Revista Ambiente \& Água, v. 13, n. 2, p. 1-17, 2018.

MORUZZI, R. B.; CONCEIÇÃO, F. T.; SARDINHA D. S.; HONDA, F. P.; NAVARRO, G. R. B. Avaliação de cargas difusas e simulação de autodepuração no Córrego da Água Branca, Itirapina (SP). Geociências, São Paulo, v. 31, n. 3, p. 447-458, 2012.

NOVOTNY, V. Water quality: Diffuse Pollution and Watershed Management. 2. ed. New York: John Wiley \& Sons, 2003. 864p. 
PALHARES, J. C. P.; GUIDONI, A. L.; STEINMETZ, R. L. R.; MULINARI, M. R.; SIGUA, G. C. Impacto de sistemas de produção pecuários/agrícolas na qualidade da água da sub bacia do rio Pinhal, Santa Catarina, Brasil. Archivos. Zootecnia, v. 61, n. 236, p. 493-504, 2012.

SANTOS, I. K. S. Proposta metodológica de quantificação de poluentes de origem difusa. 2018. 67 f. Dissertação (Mestrado Profissional em Rede em Gestão e Regulação de Recursos Hídricos) Universidade Federal de Pernambuco, Recife, 2018.

SARDINHA, D. S.; CONCEIÇÃO, F. T.; SOUZA, A. D. G.; SILVEIRA, A.; DE JULIO, M.; GONÇALVES, J. C. S. I. Avaliação da qualidade da água e autodepuração do Ribeirão do Meio, Leme (SP). Engenharia Sanitária e Ambiental, v. 13, n. 3, p. 329-338, 2008.

SMA - Secretaria Estadual do Meio Ambiente de São Paulo. Versão 1.5 do Modelo de Correlação Uso do Solo/ Qualidade de Água- MQUAL. São Paulo. 2003.

SOUZA, A. D. G.; SOUZA, A. H. A Influência da área urbana sobre a qualidade da água na bacia hidrográfica do Ribeirão dos Poços (Poços de Caldas). Holos Environment, v. 15, n. 2, p. 139-151, 2015.

SOUZA, M. A. A.; MINOTI, R. T. Relatório de Análise do Documento "Atendimento ao Ofício 1251/2009 DILIC/IBAMA - Complementações Relativas à Qualidade da Água". Brasília: UnB, 2010.

SOUZA, M. M.; GASTALDINI, M. C. C. Avaliação da qualidade da água em bacias hidrográficas com diferentes impactos antrópicos. Engenharia Sanitária e Ambiental, v. 19, p. 263-274, 2014.

STRICKLAND, J. D.; PARSONS, T. R. A manual of seawater analysis. Bulletin of the Fisheries Research Board of Canada, v. 125, p. 1-185, 1960.

TEIXEIRA, C.; TUNDISI, J. G.; KUTNER, M. B. Plankton studies in a mangrove II. The standing stock and some ecological factors. Boletim do Instituto Oceanográfico, v. 24, p. 23-41. 1965.

TUNDISI, J. G. Produção primária, "standing stock" e fracionamento do fitoplâncton na região lagunar de Cananéia. 1969.Tese (Doutorado) - Instituto Oceanográfico, Universidade de São Paulo, São Paulo, 1969.

VALDERRAMA, J. C. The simultaneous analisys of total nitrogen and phosphorus in natural waters. Marine Chemistry, v. 10, p. 109-122, 1981.

VON SPERLING, M. Introdução à qualidade das águas e ao tratamento de esgotos. 4. ed. Belo Horizonte: Editora UFMG, 2014, 452p.

YSI. Manual do Utilizador ProDSS - DOCUMENTO \#626973-01REF. 2014. Disponível em: https:/www.ysi.com/File\%20Library/Documents/Manuals/626973-YSI-ProDSS-User-ManualRevB-Portuguese.pdf. Acesso em: 30 ago. 2021. 